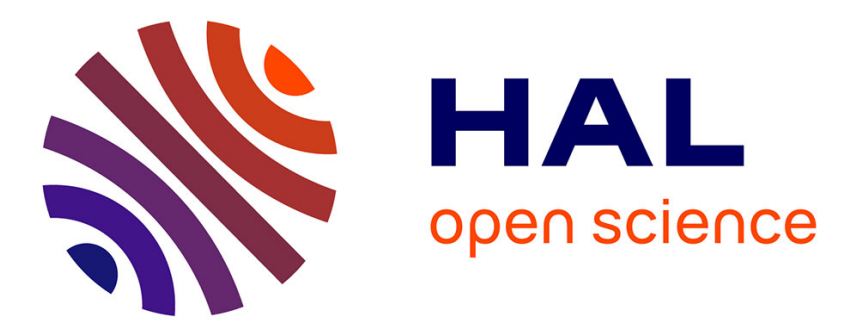

\title{
A novel colorimetric and fluorescent turn-on pH sensor with a notably large Stokes shift for its application
} Yaoyao Ning, Xiaoqing Wang, Kangjia Sheng, Lili Yang, Wei Han, Chaoni Xiao, Jianli Li, Yongmin Zhang, Shaoping Wu

\section{- To cite this version:}

Yaoyao Ning, Xiaoqing Wang, Kangjia Sheng, Lili Yang, Wei Han, et al.. A novel colorimetric and fluorescent turn-on $\mathrm{pH}$ sensor with a notably large Stokes shift for its application. New Journal of Chemistry, 2018, 42 (17), pp.14510-14516. 10.1039/C8NJ02860E . hal-01909358

\section{HAL Id: hal-01909358 https://hal.sorbonne-universite.fr/hal-01909358}

Submitted on 31 Oct 2018

HAL is a multi-disciplinary open access archive for the deposit and dissemination of scientific research documents, whether they are published or not. The documents may come from teaching and research institutions in France or abroad, or from public or private research centers.
L'archive ouverte pluridisciplinaire HAL, est destinée au dépôt et à la diffusion de documents scientifiques de niveau recherche, publiés ou non, émanant des établissements d'enseignement et de recherche français ou étrangers, des laboratoires publics ou privés. 


\title{
A novel colorimetric and fluorescent turn-on $\mathrm{pH}$ sensor with a notably large Stokes shift for its application
}

\author{
Yaoyao Ning, a,b $\S$ Xiaoqing Wang, ${ }^{c, \S}$ Kangjia Sheng, ${ }^{\text {a, b }}$ Lili Yang, a, b Wei Han, ${ }^{a}$ Chaoni Xiao, ${ }^{a}$ Jianli Li, ${ }^{c}$ \\ Yongmin Zhang ${ }^{a, b, d}$ and Shaoping $\mathrm{Wu}^{\mathrm{a}, \mathrm{b},{ }^{*}}$
}

\begin{abstract}
A novel naked-eye colorimetric and fluorescent turn-on $\mathrm{pH}$ sensor based on naphthalenone scaffold was rationally designed and facilely synthesized. The probe exhibited strong alkaline $\mathrm{pH}$-dependent $\left(\mathrm{p} K_{\mathrm{a}}=9.92\right)$ behavior, high selectivity, sensitivity, high quantum efficiency ( $\phi=0.64$ ) and rapid respond to $\mathrm{pH}$ fluctuations (within $1 \mathrm{~min}$ ) in the range of 9.0 - 14.0. In addition, probe DDTM displayed a notably large Stokes shift of $198 \mathrm{~nm}$. The response mechanism of the fluorescent probes was proposed to be caused by $\mathrm{OH}^{-}$-induced structure changes from the nonfluorescent DDTM form to the highly emissive addition product (more than 150-fold fluorescence enhancement) along with ICT changes. Live cell imaging data revealed that probe DDTM could selectively monitor pH changes with low cytotoxicity and cell membrane permeability. Therefore, this probe could be acted as an effective intracellular $\mathrm{pH}$ imaging sensor under extreme alkaline condition in the biomedical and biological fields.
\end{abstract}

\section{Introduction}

It is well known that the $\mathrm{pH}$ values are uniquely of high importance among the few chemical parameters. Specially, intracellular $\mathrm{pH}$ plays an important role in cell function and regulation such as cell volume regulation [1], vesicle trafficking, cellular metabolism [2], cell membrane polarity [3], cellular signalling, cell activation, growth, proliferation and apoptosis [4]. As an important indicator of cellular health, abnormal $\mathrm{pH}$ values of intracellular could lead to cellular functional disorders and serious diseases such as cancer [5,6], stroke [7], Alzheimer's disease [8], neurodegenerative disorders [9] and cardiovascular disease [10]. Therefore, it is extremely crucial to sense and monitor $\mathrm{pH}$ changes in living cells for investigating cellular functions and further providing insight into physiological and pathological processes.

A variety of analytical techniques have been reported to measure $\mathrm{pH}$ value including acid-base indicator titration [11], potentiometric titration [12], nuclear magnetic resonance [13], Raman sensor [14] and so on. Hence, it is essential for the health professional to have simple and effective methodologies for the rapid, selective, and sensitive detection of $\mathrm{pH}$ values in biological specimens. Fluorescent probes have been found widespread application for sensing and imaging $\mathrm{pH}$ values in living cells and tissues due to its high sensitivity, easy operation, real-time and noninvasive imaging properties [15]. However, a lot of reported $\mathrm{pH}$ probes still have some drawbacks such as low fluorescence quantum yields, poor photostability and narrow Stokes shifts. For the sake of overcoming these drawbacks, it is important to develop new longwave fluorescent probes with large Stokes shifts, and high turn-on fluorescence brightness.

Naphthalenone derivatives have been found to exhibit a variety of biological activities [16,17] and have also been surveyed for their suitability as dyes scaffold $[18,19]$. In addition, aromatic heterocyclic compounds containing a five- membered furan or thiophene unit have been extensively studied in recent years due to their impressive optical properties and excellent charge-transport properties [20,21]. Therefore, construction of naphthalenone derivatives containing heterocyclic unit will be vital in synthesis of novel organic materials with appealing photonic and electronic functionality.

As part of our ongoing program in the study of novel fluorescent dyes $[22,23]$, in the current work, a novel $\mathrm{pH}$ response fluorescent probe DDTM was rationally designed and facilely synthesized by connecting a DTC fluorophore and a dicyanomethylidene group with double bond. In DDTM, the dicyanomethylidene group was used as an acceptor moiety while the amino group acts as an electron donor to form pushpoll system. This probe displayed that ICT was conjugated organic $\pi$-systems with acceptor and donor subunits. To our surprise, the dicyanomethylidene group of probe DDTM, one of cyanide receptors, has no reaction with cyanide ion except $\mathrm{OH}^{-}$[24]. Compared with other reported pH probes [25-32], probe DDTM exhibited strong $\mathrm{pH}$-dependent behaviour, high selectivity, sensitivity and responded linearly and rapidly to respond $\mathrm{pH}$ fluctuations within the range of 9.0 - 14.0. Specially, probe DDTM displayed a notably large Stokes shift of $198 \mathrm{~nm}$ and high fluorescence quantum yields. The response mechanism of the fluorescent probes could be caused by the $\mathrm{OH}^{-}$-induced structure changes from the nonfluorescent DDTM form to the highly emissive addition product along with ICT changes. Furthermore, live cell imaging data revealed that probe DDTM could selectively monitor $\mathrm{pH}$ changes with low cytotoxicity. Therefore, this probe could be used to visualize extreme alkaline within the biomedical and biological fields (Scheme 1). 


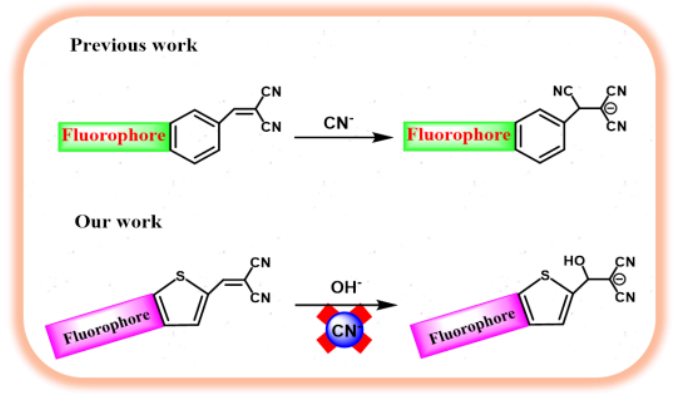

Scheme 1. Strategies to response of $\mathrm{pH}$ probe.

\section{Materials and methods}

\subsection{Materials}

All chemical reagents were purchased from commercial suppliers and used without further purification. All organic solvents used for this work were of analytical grade also without further purification. All reaction processes were monitored through thin layer chromatography (TLC) which was performed by using Merck F254 gel-60 plates. Silica gel (200 mesh) was used as the solid phase for column chromatography by Qingdao Ocean Chemicals (China). All metal ions were prepared from corresponding salts. All samples were prepared at room temperature before UV-vis and fluorescence determination. The phosphate-buffered saline (PBS) was prepared from sodium dihydrogen phosphate and disodium hydrogen phosphate. Probe standard solution dissolved in DMSO and diluted to $50 \mathrm{~mL}$ volumetric flask. Distilled water was prepared from a Millipore water purification system. All glassware was cleaned with ultrapure water for three times and dried before use.

\subsection{Instrumentation and methods}

A pH meter (Sartorius PB-10) was used to determine the $\mathrm{pH}$ value. UV-vis absorption spectra were measured at room temperature with a Shimadzu UV-2550 spectrophotometer in $1 \mathrm{~cm}$ quartz. The fluorescence spectra were taken on a Hitachi F-7000 Fluorescence spectrophotometer (Hitachi, Japan) using a $5.0 \mathrm{~nm}$ slit width in a $1 \times 1 \mathrm{~cm}$ quartz cell. The cells fluorescence imaging was obtained by laser scanning confocal fluorescence microscopy Olympus FV1000 (Olympus Corporation, Tokyo, Japan). High resolution mass spectra (HRMS) were recorded on a micro TOF-QIl mass spectrometer. ${ }^{1} \mathrm{H}$ NMR and ${ }^{13} \mathrm{C}$ NMR spectra were obtained by Varian Gemini 2000 DMX600 MHz FT NMR spectrometers using $\mathrm{CDCl}_{3} / \mathrm{DMSO}$ $d_{6}$ as solvent and TMS as internal standard. The chemical shifts were represented by ppm. The quantum yield was measured at room temperature referenced to Quinine sulphate dehydrates in aqueous solution of $0.1 \mathrm{M}$ sulfuric acid. The structures of synthesized compounds were characterized by HRMS, ${ }^{1} \mathrm{H}$ NMR, ${ }^{13} \mathrm{C}$ NMR and the related spectra are shown in the Supplementary Information.
2.3. Synthesis of compound 2- ((7- (dimethylamino) $-4,5-$ dihydronaphtho $[1,2-b]$ thiophen - 2-yl) methylene) malononitrile (DDTM)

A solution of DTC ${ }^{[33]}(0.0500 \mathrm{~g}, 0.19 \mathrm{mmol}, 1.0$ equiv.) and malononitrile $(0.0130 \mathrm{~g}, 0.19 \mathrm{mmol}, 1.0$ equiv.) in anhydrous $\mathrm{CH}_{2} \mathrm{Cl}_{2}(5 \mathrm{~mL})$ was treated with triethylamine $(0.2 \mathrm{~mL})$ at room temperature under argon. The reaction mixture was stirred at room temperature for $3 \mathrm{~h}$. The solvent was evaporated under reduced pressure, and the residue was purified by silica gel column chromatography. (Yield: $40.5 \%, \mathrm{R}_{\mathrm{f}}=0.5$, PE: EtOAc= 3:1). ${ }^{1} \mathrm{H}$ NMR (600 MHz, $\left.\mathrm{CDCl}_{3}\right) \delta 7.58(\mathrm{~s}, 1 \mathrm{H}), 7.45(\mathrm{~s}, 1 \mathrm{H}), 7.36$ $(\mathrm{d}, \mathrm{J}=8.5 \mathrm{~Hz}, 1 \mathrm{H}), 6.62-6.48(\mathrm{~m}, 2 \mathrm{H}), 3.04(\mathrm{~s}, 6 \mathrm{H}), 2.96-2.87(\mathrm{~m}$, $2 \mathrm{H}), 2.81$ (dd, J = 23.5, $16.5 \mathrm{~Hz}, 2 \mathrm{H}) .{ }^{13} \mathrm{C} \mathrm{NMR}\left(151 \mathrm{MHz}, \mathrm{CDCl}_{3}\right)$ $\delta 152.53,151.97,149.76,139.29,138.62,136.61,131.25$, $130.63,126.94,118.68,114.93,111.54,71.69,40.62,32.28$, 30.39, 30.06, 23.90. HRMS $\left(\mathrm{C}_{18} \mathrm{H}_{15} \mathrm{~N}_{3} \mathrm{~S}\right)$ : calcd. for $[\mathrm{M}+\mathrm{H}]^{+}$ 306.1059; found: $[\mathrm{M}+\mathrm{H}]+306.0987$.

\subsection{Titration experiments of probe DDTM}

For UV-vis and fluorescence titrations, stock solution of probe DDTM $(1.0 \mathrm{mM})$ was prepared in DMSO solution. Different portions of the stock solution were then diluted to different concentrations for further usage. Generally, $50 \mu \mathrm{L}$ of probe DDTM solution was added into $5 \mathrm{~mL}$ of buffer solution (10 mM PBS buffer, 20\% DMSO) in a colorimetric tube. The other ions were dissolved in deionized water and added to the probe solution under the same condition. The $\mathrm{pH}$ variations of the solution were adjusted by adding the different volumes of $\mathrm{NaOH}(0.1 \mathrm{M}$ or $1.0 \mathrm{M})$. The resulting solution was shaken well and incubated for $5 \mathrm{~min}$ at room temperature before measurements. The spectra of these solutions were recorded by means of fluorescence method. Fluorescence measurements were carried out with a slit width of $5 \mathrm{~nm}\left(\lambda_{\mathrm{ex}}=\right.$ $380 \mathrm{~nm}$ ) in $10 \mathrm{~mm}$ quartz cuvettes at room temperature and the scan rate was $1200 \mathrm{~nm} / \mathrm{min}$.

\subsection{Cytotoxicity experiments}

HeLa cells were purchased from the ATCC Cell Bank. Cell counting kit-8 (CCK-8) was used to detect the cytotoxicity of probe DDTM. Cells were seeded in 96-well plates at a concentration of $2 \times 10^{4}$ cells per well and cultured for $24 \mathrm{~h}$ in DMEM (supplemented with $10 \%$ fetal bovine serum (FBS)) in an incubator $\left(37{ }^{\circ} \mathrm{C}, 5 \% \mathrm{CO}_{2}\right)$. After the cells were incubated with probe DDTM at different concentrations $(0,5,10,15,20$ and $25 \mu \mathrm{M})$ for $24 \mathrm{~h}, \mathrm{CCK}-8(10 \mu \mathrm{L})$ was added to each well of the 96 -well plate for $3 \mathrm{~h}$ at $37^{\circ} \mathrm{C}$, the absorbance was measured at $450 \mathrm{~nm}$ using a microplate reader. Five replicates were done for each treatment group.

\subsection{Cell imaging of probe DDTM}

HeLa cells were placed on a $20 \mathrm{~mm}$ diameter glass bottomed culture dish and allowed to adhere for $24 \mathrm{~h}$ for intracellular imaging of $\mathrm{OH}^{-}$. Before confocal scanning imaging, these cells were incubated with $10 \mu \mathrm{M}$ of probe DDTM at $37^{\circ} \mathrm{Cfor} 30 \mathrm{~min}$ followed by washing three times with phosphate-buffered saline (PBS, $\mathrm{pH}=7.4$ ). Subsequently, the cells were washed with PBS for three times to remove excess DDTM, then in situ treated with different $\mathrm{pH}$ value solution $\mathrm{pH} 10.0$ and 12.0, 
respectively), cells were then visualized with a FV1000 laser scanning confocal microscope. The excitation wavelength was set to $405 \mathrm{~nm}$ and $543 \mathrm{~nm}$.

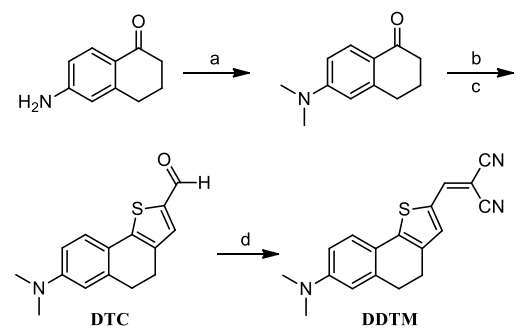

Reagents and Conditions: (a) $\mathrm{CH}_{3} \mathrm{I}, \mathrm{K}_{2} \mathrm{CO}_{3}, \mathrm{DMF}, 50^{\circ} \mathrm{C} 24 \mathrm{~h}, 54 \%$; (b) $\mathrm{POCl}_{3}$, DMF, $90^{\circ} \mathrm{C}$ reflux $5 \mathrm{~h}$; (c) $\mathrm{Na}_{2} \mathrm{~S} \cdot 9 \mathrm{H}_{2} \mathrm{O}$, Chloroacetaldehyde, $\mathrm{K}_{2} \mathrm{CO}_{3}, \mathrm{DMF}, 42 \%$ in two steps; (d) Malononitrile, $\mathrm{Et}_{3} \mathrm{~N}, \mathrm{CH}_{2} \mathrm{Cl}_{2}$, R.T. $3 \mathrm{~h}, 41 \%$.

Scheme 2. Synthesis of probe DDTM.

\section{Results and discussion}

\subsection{Synthesis of probe DDTM}

The general synthetic route of probe DDTM was shown in Scheme 2. DTC was conveniently synthesized according to our previous work. Then DTC reacted with malononitrile to obtain the probe DDTM by Knoevenagel condensation at moderate yield in one step. The structure of probe DDTM was characterized and confirmed by ${ }^{1} \mathrm{H} N M R,{ }^{13} \mathrm{C}$ NMR and HRMS data.

\subsection{Photophysical properties of probe DDTM}

Probe DDTM exhibited good solubility in common organic solvents such as $\mathrm{CH}_{2} \mathrm{Cl}_{2}, \mathrm{CHCl}_{3}$, THF and DMSO. On one hand, probe DDTM was slightly soluble in water but DMSO could help increase its water solubility. On the other hand, the respond of probe DDTM toward $\mathrm{OH}^{-}$has the maximum fluorescence emission wavelength in DMSO solvent (Fig. S1). So DMSO was preferred to be co-solvent in the photophysical properties experiment. In addition, the maximum emission wavelength of probe DDTM toward $\mathrm{OH}^{-}$was obtained in PBS buffer (Fig. S2). Hence, probe DDTM could dissolve completely in a mixture of DMSO/PBS buffer (10 mM PBS buffer, 20\% DMSO) and the corresponding solution exhibited an efficient fluorescent turn on mode for $\mathrm{pH}$ value change within 1 minute. The colour of probe DDTM in a mixture of DMSO/PBS buffer $\mathrm{pH} 7.4$ was light pink with a distinct absorption band at 430 $\mathrm{nm}$. On the contrary, the colour of the mixture was changed from light pink to yellow and the absorbance of probe DDTM drastically increases at $430 \mathrm{~nm}$ when $\mathrm{pH}$ value increased to 11.0 (Fig. S3). The change of colour was readily observed by naked-eye.

In addition, no emission wavelength of probe DDTM was appeared from $450 \mathrm{~nm}$ to $650 \mathrm{~nm}$ with the fluorescence quantum efficiency of 0.01 (Quinine sulphate dehydrate in 0.1 $\mathrm{M} \mathrm{H}_{2} \mathrm{SO}_{4}$ was used as the main standard, $\Phi_{\mathrm{S}}=0.54, \lambda_{\mathrm{ex}}=365$ $\mathrm{nm}$ ). The low quantum efficiency was occurred by ICT process from the amino group of naphthalenone scaffold as an electron acceptor group to the dicyanovinyl moiety as an electron acceptor group by its $\pi$-conjugation. To our delight, the remarkable fluorescence enhancement was observed more than 150-fold and the quantum efficiency increased to 0.64 due to the disruption of ICT phenomena of probe DDTM when $\mathrm{pH}$ value increased to 11.0 , the fluorescence colour was changed from colourless to orange to yellow with the maximum emission wavelength at $578 \mathrm{~nm}$. The dicyanovinyl group could be modulated by reacting with $\mathrm{OH}^{-}$, and this nucleophilic addition reaction could finally interrupt the $\pi$ conjugation leading to the turn on mode of this detection.

\subsection{UV-vis absorbance and fluorescence response of probe DDTM to $\mathrm{pH}$}

The UV-Vis and fluorescence properties of probe DDTM were measured in a mixture of DMSO/PBS buffer system (10 mM PBS buffer, 20\% DMSO) for detecting pH changes. As shown in Fig. 1(a), the absorbance at $430 \mathrm{~nm}$ was gradually increased and had a good linear relationship with $\mathrm{pH}$ value in the range from 10.5 to $13.5\left(R^{2}=0.9946\right)$ along with the $\mathrm{pH}$ value increase. At the same time, the solution colour was drastically changed from light pink to yellow accompanied with these absorption changes. So probe DDTM could be used as nakedeye-visible $\mathrm{pH}$ indicators in aqueous media due to their sensitive colour response to solution $\mathrm{pH}$ change.
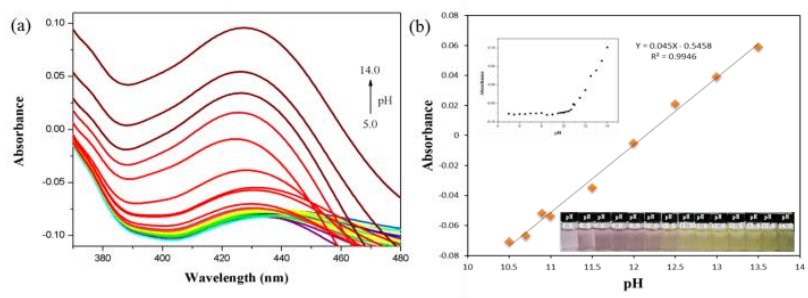

Fig. 1. (a) UV-Vis absorption spectra of probe DDTM (10 $\mu \mathrm{M}$ in $10 \mathrm{mM}$ PBS buffer, 20\% DMSO) in accurate $\mathrm{pH}$ values ranging from 5.0 to 14.0 at $25^{\circ} \mathrm{C}$. (b) Linear relationship of UV-Vis absorption at $430 \mathrm{~nm}$ and $\mathrm{pH}$ values from 10.5 to 13.5. Inset: the colour of probe DDTM in the different $\mathrm{pH}$ values under daylight lamp.

Further for fluorescent responses, as depicted in Fig. 2, probe DDTM itself had no fluorescence intensity at $578 \mathrm{~nm}$, however, the fluorescence intensity increased with a concomitant enhancement in $\mathrm{pH}$ changes. With the variation of $\mathrm{pH}$ from 8.0 to 14.0 , the probe showed turn-on fluorescence. Notably, a good linearity $\left(R^{2}=0.9958\right)$ between the florescence intensities with $\mathrm{pH}$ in the range of 9.5-10.7 was obtained, the regression equation was $Y=2324.5 X-21250$. Additionally, on the basis of the Henderson-Hasselbalch equation $\left(\log \left[\left(I_{\max }-\mid\right) /\left(I-I_{\min }\right)\right]=\mathrm{pH}-\right.$ $\mathrm{pK}_{\mathrm{a}}$ ), the $\mathrm{pK}_{\mathrm{a}}$ value of probe DDTM was determined to be 9.92 by analysis of the dependency of fluorescence intensities at 578 nm (Fig. 3). These results demonstrated that probe DDTM could be used to detect $\mathrm{pH}$ value quantitatively in extreme alkaline solution. 

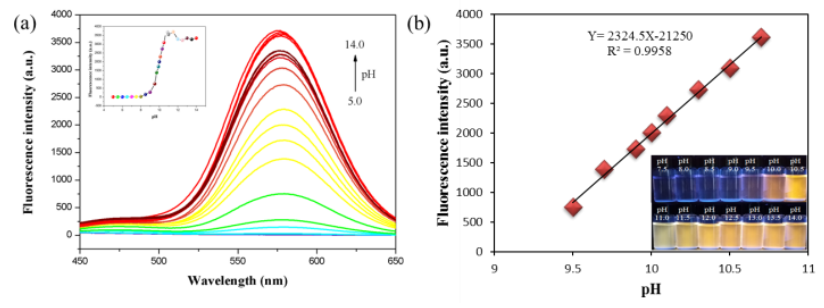

Fig. 2. (a) Emission spectra of probe DDTM (10 $\mu \mathrm{M}$ in $10 \mathrm{mM}$ PBS buffer, 20\% DMSO) in accurate $\mathrm{pH}$ values ranging from 5.0 to 14.0 at $25^{\circ} \mathrm{C}\left(\lambda_{\text {ex }}=380 \mathrm{~nm}\right.$, slit: $\left.5.0 \mathrm{~nm} / 5.0 \mathrm{~nm}\right)$. Inset: Fluorescence intensity at $578 \mathrm{~nm}$ by $\mathrm{pH}$ values according to the fluorescence titration ( $\mathrm{pH}$ 5.0 14.0). (b) The linear relationship of fluorescence intensity at $578 \mathrm{~nm}$ and $\mathrm{pH}$ values from 9.5 to 10.7. Inset: the color of probe DDTM in the different pH values under UV $365 \mathrm{~nm}$.

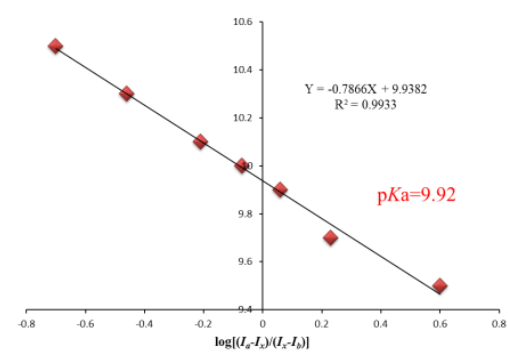

Fig. 3. Linear regression relationship between the $\mathrm{pH}$ value and log $\left[\left(F_{\max }-F_{x}\right) /\left(F_{x}-F_{\min }\right)\right]$.

\subsection{Selectivity experiment of probe DDTM to $\mathrm{pH}$}

The intracellular environment is quite complex and many biological molecules are present, such as amino acids, cysteine (Cys), homocysteine (Hcy) and glutathione (GSH), metal ions and reactive oxygen species (ROS) and so on. In order to verify whether these biomolecules could disturb the $\mathrm{pH}$ measurement efficiently in living cells, the selectivity of DDTM to alkaline over these species was investigated at $\mathrm{pH}$ 11.0, the results were shown in Fig. 4(a), metal ions and reactive oxygen species showed very weak fluorescence intensity at $578 \mathrm{~nm}$. In contrast, the strong fluorescence signal of probe DDTM was observed at $578 \mathrm{~nm}$ in alkaline solutions. Meanwhile, all biomolecules of fluorescence response in neutral and alkaline environments were evaluated to survey competition experiments. As shown in Fig. 4(b), addition of biomolecules has no interference on the fluorescent spectroscopic changes to $\mathrm{pH}$ under the testing conditions. All these results indicated that probe DDTM could serve as a highly selective chemosensor for $\mathrm{pH}$ change in extreme alkaline solution.
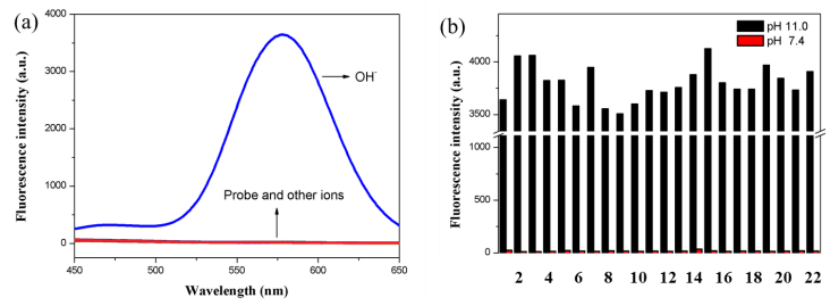

Fig. 4. (a) Emission spectra of probe DDTM in the presence of different metal ions and biologically relevant analytes $(10 \mu \mathrm{M})$ in the $\mathrm{pH} 11.0$ solution. (b) Fluorescence respond of probe DDTM (10 $\mu \mathrm{M}$ ) in the presence of different metal ions and biologically relevant analytes $1.0 \mathrm{mM}$ in the two $\mathrm{pH}$ values. 1: Blank; 2: $\mathrm{AcO}^{-} ; 3: \mathrm{ClO}_{4}^{-} ; 4$ : $\mathrm{CO}_{3}{ }^{2-} ;$ 5: $\mathrm{ClO}^{-} ;$6: $\mathrm{NO}_{3}{ }^{-} ; 7: \mathrm{ONOO}^{-} ; 8: \mathrm{SO}_{3}{ }^{2-}$; 9: $\mathrm{Cys} ; 10: \mathrm{GSH} ; 11: \mathrm{H}_{2} \mathrm{O}_{2}$ (0.5 mM); 12: $\mathrm{Ba}^{2+} ; 13: \mathrm{Ca}^{2+} ; 14: \mathrm{CN}^{-} ; 15: \mathrm{Cu}^{2+} ; 16: \mathrm{Fe}^{3+} ; 17: \mathrm{Hg}^{2+} ; 18:$ $\mathrm{K}^{+}$; 19: $\mathrm{Mg}^{2+} ; 20: \mathrm{Na}^{+}$; 21: DTT; 22: $\mathrm{H}_{2} \mathrm{~S}$. $\left(\lambda_{\mathrm{ex}}=380 \mathrm{~nm}\right.$, slit: $5.0 \mathrm{~nm} / 5.0$ $\mathrm{nm})$.

\subsection{Time-dependent effect and reversibility study of probe DDTM}

The time-dependent course analysis showed that probe DDTM could quickly respond to $\mathrm{pH}$ value change for less than one minute at $\mathrm{pH}$ 11.0. As shown in Fig. 5(a), after addition of DDTM to PBS buffer solutions at pH 7.4 and 11.0 at room temperature, respectively, the fluorescence intensity of the probe instantly reached equilibrium and remained unchanged for at least $30 \mathrm{~min}$. The experimental results proved that probe DDTM has rapid respond to $\mathrm{pH}$ changes in extreme alkaline solution.

As for $\mathrm{pH}$ probes, the reversibility was one of the vital requirements for practical applications. Therefore, the reversibility of probe DDTM was explored that the $\mathrm{pH}$ value of the solution was switched back and forth between $\mathrm{pH} 4.0$ and 11.0 using concentrated hydrochloric acid and aqueous sodium hydroxide. As shown in Fig. 5(b), probe DDTM exhibited a highly reversible response to $\mathrm{pH}$ and the response time in different $\mathrm{pH}$ values were less than $10 \mathrm{~s}$. Switching between the fluorescence on/off states could be repeated along with the colour change repeatedly between colourless $(\mathrm{pH} 4.0)$ and yellow ( $\mathrm{pH}$ 11.0). These results demonstrated that probe DDTM could show quick and reversible responses to $\mathrm{pH}$ changes, and also be potentially useful to real-time monitor $\mathrm{pH}$ value changes in extreme alkaline solution.
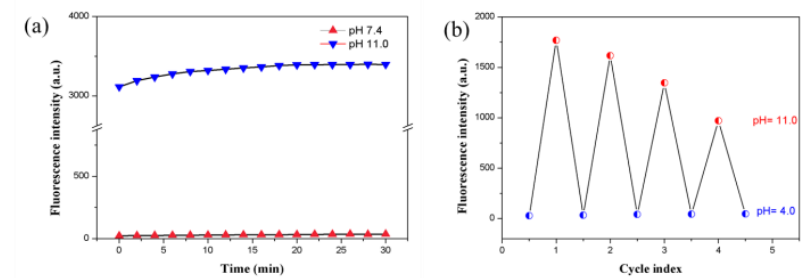

Fig. 5. (a) Time course of fluorescence intensity of probe DDTM (10 $\mu \mathrm{M}$ in $10 \mathrm{mM}$ PBS buffer, 20\% DMSO) in the two $\mathrm{pH}$ values. (b) $\mathrm{pH}$ reversibility of probe DDTM (10 $\mu \mathrm{M}$ in $10 \mathrm{mM}$ PBS buffer, $20 \%$ DMSO) between pH 4.0 and $\mathrm{pH} 11.0$ at $25{ }^{\circ} \mathrm{C}\left(\lambda_{\mathrm{ex}}=380 \mathrm{~nm}\right.$, slit: 5.0 $\mathrm{nm} / 5.0 \mathrm{~nm})$.

\subsection{Proposed detection mechanism and theoretical computation}

The mechanism for the fluorescence enhancement of probe DDTM was proposed as shown in Fig. 6. In alkaline solution, hydroxyl ion reacted as nucleophilic reagent on the double bond of dicyanovinyl group in probe DDTM to give the addition intermediate, which could finally interrupt the $\pi$ conjugation leading to produce strong fluorescence. Then 
hydroxyl of the addition intermediate could be occurred in protonation process in acid condition, finally probe DDTM is regenerated and the water molecule is released. To further confirm the proposed detection mechanism of probe DDTM towards hydroxyl, probe DDTM was reacted with tetrabutyl ammonium hydroxide at room temperature for $10 \mathrm{~min}$ in $\mathrm{MeOH}$ solution, then the reaction solution was diluted appropriately and tested by mass spectroscopy, an expected signal at $\mathrm{m} / \mathrm{z} 322.9321$ corresponding to addition intermediate [probe DDTM + OH] ${ }^{-}$was observed (Fig. S4), and these data were consistent with the proposed mechanism.

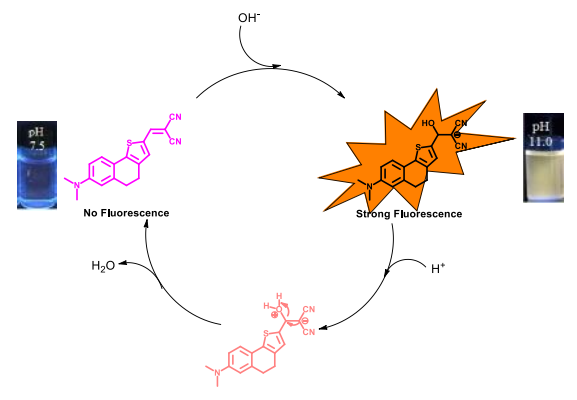

Fig. 6. Proposed mechanism of probe DDTM towards $\mathrm{pH}$ changes.

To better understand the optical responses of probe DDTM upon adding with $\mathrm{OH}^{-}$, density functional theory (DFT) calculations were performed using the CAM-B3LYP/6-311+G(d, p) level of Gaussian 09 program [34,35]. The solvent effects were taken into account in water through the polarizable continuum model (PCM) [36]. The optimized structures of DDTM and DDTM-OH ${ }^{-}$were shown in Fig. 7. The molecular backbone of the DDTM was nearly coplanar while the dihedral angle of thiophene ring and dicyanovinyl group in the DDTM$\mathrm{OH}^{-}$was $48.9^{\circ}$, indicating the dicyanovinyl group was twisted in response to $\mathrm{OH}^{-}$.

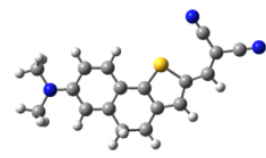

DDTM

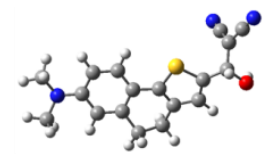

DDTM-OH
Fig. 7. Optimized structures of DDTM and DDTM-OH at the CAMB3LYP/6-311+G(d, p)/PCM theoretical level.

Molecular orbital surfaces of the HOMO and LUMO for compound DDTM and DDTM-OH- were displayed in Fig. 8. For DDTM, the electron density in the HOMO was distributed over the whole molecular while that in the LUMO was mainly concentrated on the thiophene ring and dicyanovinyl group, respectively. As for DDTM-OH', the electron in HOMO and LUMO orbitals was mostly spread over the moiety of DTC. Obviously, there was no ICT process occurred in the DDTM$\mathrm{OH}^{-}$, in that a $\mathrm{sp}^{3}$ hybridized carbon atom existed in vinyl moiety of dicyanomethylidene and dicyanomethylidene twisted. The interruption of the ICT process also resulted in the increased HOMO-LUMO energy gap of DDTM-OH- (6.39 eV) in comparison with that of the DDTM $(4.63 \mathrm{eV})$ and is also explained for the appearance of a new absorption band at 430 $\mathrm{nm}$ in the absorption spectrum of DDTM-OH-. Therefore, these DFT calculations verified that $\mathrm{OH}$ - was bound to the vinyl group of probe DDTM and are in good agreement with the experimental results.

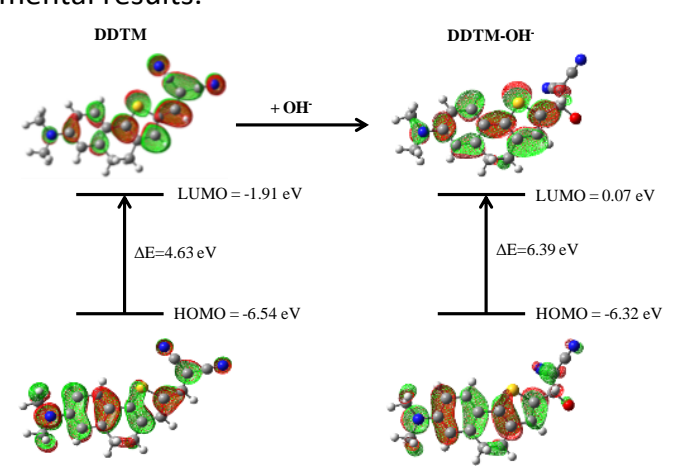

Fig. 8. HOMO-LUMO energy levels and frontier molecular orbitals of probe DDTM and the adduct DDTM-OH-

\subsection{Cytotoxicity and fluorescence imaging for living cells}

Firstly, the cytotoxic effects of probe DDTM were studied in order to evaluate its imaging performance in vivo. MTT, a standard cell viability protocol, was employed to evaluate the cytotoxicity of probe DDTM on HeLa cells by treating HeLa cells with the probe for $48 \mathrm{~h}$. The probe showed low cytotoxicity and excellent compatibility with more than $80 \%$ viability at concentration of $25 \mu \mathrm{M}$ under experimental conditions (Fig. S3).

Next, the cellular imaging assays were performed to verify whether probe DDTM could be applied for determining $\mathrm{pH}$ changes in the biological application. HeLa cells were incubated with probe DDTM at pH 7.4, 10.0 and 12.0 for 5 $\mathrm{min}$, after that intracellular fluorescence was monitored by confocal microscopy (Fig. 9). Under neutral condition, no fluorescence was observed. On the contrary, moderate fluorescence was observed when cells were incubated with probe DDTM at $\mathrm{pH}$ 10.0. Furthermore, the strong blue fluorescence was observed at $\mathrm{pH}$ 12.0. At the same time, the similar results were obtained in red channel when excitation wavelength was $543 \mathrm{~nm}$. These results indicated that probe DDTM displays sensitive fluorescence enhances in a $\mathrm{pH}$ dependent manner in living cells system.

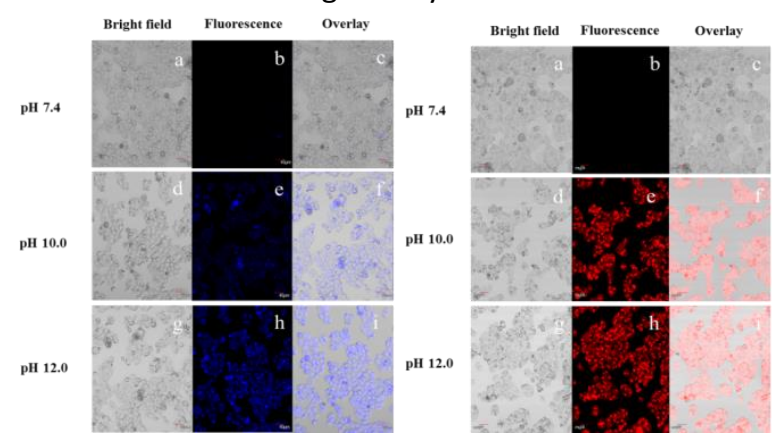

Fig. 9. Confocal fluorescent imaging of HeLa cells incubated with probe DDTM $(10 \mu \mathrm{M})$ at $\mathrm{pH} 7.4(\mathrm{a}, \mathrm{b}, \mathrm{c}), 10.0(\mathrm{~d}, \mathrm{e}, \mathrm{f})$ and $12.0(\mathrm{~g}, \mathrm{~h}$, 
i) for $5 \mathrm{~min}$, respectively. Left: Excitation wavelength was $405 \mathrm{~nm}$. Right: Excitation wavelength was $543 \mathrm{~nm}$. Scale bar: $40 \mu \mathrm{m}$.

Additionally, dynamic fluorescence imaging was also occurred to investigate the process of DTTM diffusing into cells and the change of fluorescence intensity. As shown in Fig. 10, the fluorescence of DDTM was obtained at different time-points via confocal laser scanning microscope. After addition of DDTM in pH 12.0 alkaline solution, the fluorescence intensity of the HeLa cells had no change and barely any fluorescence quenching was observed until $30 \mathrm{~min}$ at $405 \mathrm{~nm}$ and $543 \mathrm{~nm}$. These cell experiments demonstrated that probe DDTM has excellent stability and biological compatibility in living cells, and could be used to mark the change of $\mathrm{pH}$ in living cells.

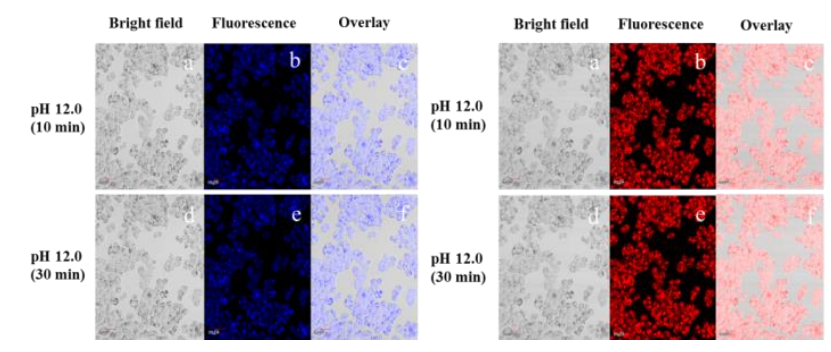

Fig. 10. Dynamic fluorescence images of living HeLa cells on incubation with $10 \mu \mathrm{M}$ DDTM for different times $10 \min (a, b, c)$ and $30 \mathrm{~min}(\mathrm{~d}, \mathrm{e}, \mathrm{f})$ in $\mathrm{pH} 12.0$ medium. Left: Excitation wavelength was $405 \mathrm{~nm}$. Right: Excitation wavelength was $543 \mathrm{~nm}$. Scale bar: 40 $\mu \mathrm{m}$.

\subsection{Practical application of probe DDTM in pH test strips}

In order to further explore the practical application of probe DDTM, pH test strips were prepared and utilized to sense different $\mathrm{pH}$ according to the excellent properties of probe DDTM. The test strip was prepared by immersing filter papers in probe DDTM solution (10 $\mu \mathrm{M}$ in $\mathbf{2 0} \%$ DMSO). After drying in the air, the strip displayed different colour change when the test strips immersed in different $\mathrm{pH}$ solution. As shown in Fig. 11, the changes of colour in different $\mathrm{pH}$ solution were observed in naked eyes and fluorescent light, respectively. Therefore, the distinct colour changes promoted probe DDTM to be conveniently used for precise $\mathrm{pH}$ paper preparation in real time applications.

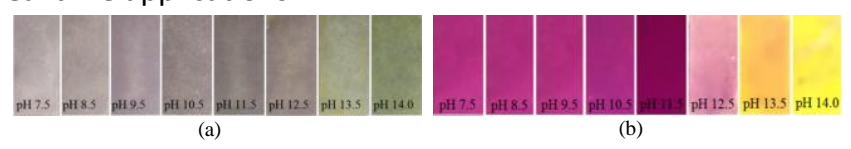

Fig. 11. Photographs of colorimetric responses of probe DDTM test strips with different pH solutions. (a) Naked eye in visible light. (b) Fluorescence colour changes under 365 nm UV lamp.

\section{Conclusions}

In summary, a novel pH-sensitive colorimetric sensors based on naphthalenone scaffold was designed and synthesized. Probe DDTM showed a naked eye visible colour changes from light pink to yellow, and the fluorescence colour was changed from colourless to orange to yellow in the range $\mathrm{pH}$ 9.0-14.0. In addition, the probe exhibited strong $\mathrm{pH}$-dependent behaviour, high selectivity and rapidly respond to $\mathrm{pH}$ fluctuations within the range of 9.0 - 14.0. Furthermore, probe DDTM displayed a notably large Stokes shift of $198 \mathrm{~nm}$. Live cell imaging data revealed that probe DDTM could selectively monitor $\mathrm{pH}$ changes with low cytotoxicity and cell membrane permeability. Therefore, the probe could be acted as an effective intracellular $\mathrm{pH}$ imaging agent under extreme alkaline conditions in the biomedical and biological fields.

\section{Conflicts of interest}

There are no conflicts of interest to declare.

\section{Acknowledgements}

We sincerely thank the Program for Changjiang Scholars and Innovative Research Team in University (No. IRT_15R55), the Science Foundation of Northwest University (No. 15NW17), the International Science \& Technology Cooperation Program of Shaanxi Province (No. 2016KW-003) and Opening Foundation of Key Laboratory of Resource Biology and Biotechnology in Western China (Northwest University), Ministry of Education.

\section{Notes and references}

[1] S. C. Burleigh, T. van de Laar, C. J. M. Stroop, W. M. J. van Grunsven, N. O'Donoghue, P. M. Rudd, G. P. Davey, BMC Biotechnol., 2011, 11, 9511.

[2] S. Humez, M. Monet, F. van Coppenolle, P. Delcour, N. Prevarskaya, Am. J. Physiol. Cell Physiol., 2004, 287, 1733-1746.

[3] A. L. Edinger, C. B. Thompson, Curr. Opin. Cell Biol., 2005, 16, 663-669.

[4] A. C. Johansson, H. Appelqvist, C. Nilsson, K. Kagedal, K. Roberg, K. Ollinger, Apoptosis., 2010, 15, 527-540.

[5] V. Estrella, T. Chen, M. Lloyd, J. Wojtkowiak, H. H. Cornnell, A. IbrahimHashim, K. Bailey, Y. Balagurunathan, J. M. Rothberg, B. F. Sloane, J. Johnson, R. A. Gatenby, R. J. Gillies, Cancer Res., 2013, 73, 1524-1535.

[6] B. A. Webb, M. Chimenti, M. P. Jacobson, D. L. Barber, Nat. Rev. Cancer., 2011, 11, 671-677.

[7] T. Myochin, K. Kiyose, K. Hanaoka, H. Kojima, T. Terai, T. Nagano, J. Am. Chem. Soc., 2011, 133, 3401-3409.

[8] T. A. Davies, R. E. Fine, R. J. Johnson, C. A. Levesque, W. H. Rathbun, K.F. Seetoo, S.J. Smith, G. Strohmeier, L. Volicer, L. Delva, E.R. Simons, Biochem. Biophys. Res. Commun., 1993, 194, 537-543.

[9] S. Harguindey, S. J. Reshkin, G. Orive, J. L. Arranz, E. Anitua, Curr. Alzheimer Res., 2007, 4, 53-65.

[10] R. D. Vaughan-Jones, K. W. Spitzer, P. Swietach, Intracellular pH regulation in heart, J. Mol. Cell. Cardiol., 2009, 46, 318-331.

[11] W. Dorota, A. Tobias, M. Colette, Anal. Chem., 2014, 86, 15-29.

[12] J. Zhou, L. Zhang, Y. Tian, Anal. Chem., 2016, 88, 2113-2118.

[13] S. He, R. P. Mason, S. Hunjan, V. D. Mehta, V. Arora, R. Katipally, P. V. Kulkarni, P. P. Antich, Bioorg. Med. Chem., 1998, 6, 1631-1639.

[14] L. S. Lawson, J. W. Chan, T. Huser, Nanoscale., 2014, 6, 7971-7980.

[15] J. Yin, Y. Hu, J. Yoon, Chem. Soc. Rev., 2015, 44, 4619-4644.

[16] C. Dax, M. Coincon, J. Sygusch, C. Blonski, Biochemistry., 2005, 44, 54305443.

[17] L. W. Lawrence Woo, N. M. Howarth, A. Purohit, H. A. M. Hejaz, M. J. Reed, B. V. L. Potter, J. Med. Chem., 1998, 41, 1068-1083.

[18] G. Niu, W. Liu, H. Xiao, H. Zhang, J. Chen, Q. Dai, J. Ge, J. Wu, P. Wang, 
Chem. Asian. J., 2015, 11, 498-504.

[19] H. Chen, Y. Tang, M. Ren, W. Lin, Chem. Sci., 2016, 7, 1896-1903.

[20] N. J. Greco, Y. Tor, Tetrahedron., 2007, 63, 3515-3527.

[21] S. C. Rasmussen, S. J. Evenson, C. B. Mccausland, Chem. Commun., 2015, 51, 4528-4543.

[22] M. She, S. Wu, Z. Wang, S. Ma, Z. Yang, B. Yin, P. Liu, S. Zhang, J. Li, Sensor. Actuat. B-Chem., 2017, 247, 129-138.

[23] X. Jin, S. Wu, M. She, Y. Jia, L. Hao, B. Yin, L. Wang, M. Obst, Y. Shen, Y. Zhang, J. Li, Anal. Chem., 2016, 88, 11253-11260.

[24] (a) Z. Liu, X. Wang, Z. Yang, W. He, J. Org. Chem., 2011, 76, 10286 10290; (b) X. Cheng, Y. Zhou, J. Qin, Z. Li, ACS. Appl. Mater. Interfaces., 2012, 4, 2133-2138; (c) W. Lin, S. Fang, J. Hu, H. Tsai, K. Chen, Anal. Chem., 2014, 86, 4648-4652; (d) W. Chen, Z. Zhang, X. Li, H. Agren, J. Su, RSC Adv., 2015, 5, 12191-12201; (e) J. Orrego-Hernandez, J. Portilla, J. Org. Chem., 2017, 82, 13376-13385.

[25] X. Li, Y. Yue, Y. Wen, C. Yin, F. Huo, Dyes Pigm., 2016, 134, 291-296.

[26] Y. Ge, P. Wei, T. Wang, X. Cao, D. Zhang, F. Li, Sensor. Actuat. B-Chem. 2018, 254, 314-320.

[27] J. Chao, K. Song, H. Wang, Z. Li, Y. Zhang, C. Yin, F. Huo, J. Wang, T. Zhang, RSC Adv., 2017, 7, 964-970.

[28] Y. Ge, A. Liu, J. Dong, G. Duan, X. Cao, F. Li, Sensor. Actuat. B-Chem. 2017, 247, 46-52.

[29] G. Chen, Q. Fu, F. Yu, R. Ren, Y. Liu, Z. Cao, G. Li, X. Zhao, L. Chen, H. Wang, J. You, Anal. Chem., 2017, 89, 8509-8516.

[30] Y. Wen, W. Zhang, T. Liu, F. Huo, C. Yin, Anal. Chem., 2017, 89, 1186911874

[31] G. Niu, P. Zhang, W. Liu, M. Wang, H. Zhang, J. Wu, L. Zhang, P. Wang, Anal. Chem., 2017, 89, 1922-1929.

[32] X. Liu, Y. Su, H. Tian, L. Yang, H. Zhang, X. Song, G. W. Foley, Anal. Chem., 2017, 89, 7038-7045.

[33] Y. Ning, J. Cui, Y. Lu, X. Wang, C. Xiao, S. Wu, J. Li, Y. Zhang, Sensor Actuat. B-Chem., 2018, 269, 322-330.

[34] T. Yanai, D. P. Tew, N. C. Handy, Chem. Phys. Lett., 2004, 393, 51-57.

[35] C. Lee, W. Yang, R.G. Parr, Phys. Rev. B., 1988, 37, 85-789.

[36] J. Tomasi, B. Mennucci, E. Cancès, J. Mol. Struct., (THEOCHEM) 1999 464, 211-226. 